\title{
SIN PRECEDENTES: UNA MIRADA ESCÉPTICA A LA REGLA DEL STARE DECISIS*
}

\author{
Álvaro Núñez Vaquero* \\ Universidad Austral de Chile
}

\author{
«El precedente es como una madre judía. \\ No tienes que hacer lo que te dice, \\ pero te hará sentir terriblemente mal si no lo haces» \\ (S. SEDLEY, On Never Doing Anything for the First Time, \\ Reform Club, London, 2001, Atkin Lecture, 6)
}

RESUMEN: El presente trabajo pretende demostrar como si bien un ordenamiento sin ningún tipo de regla del precedente resulta disfuncional, tanto la identificación de su ratio decidendi como sus condiciones de aplicación resultan altamente indeterminadas. Para demostrar tal tesis se procede mediante cuatro pasos. En primer lugar, se intenta esclarecer el concepto de precedente, adoptando un concepto amplio, y analizando en qué sentidos aquellos pueden ser vinculantes. En segundo lugar, se plantea la pregunta acerca de cuándo podemos afirmar que un ordenamiento jurídico contiene una regla del precedente vinculante. En tercer lugar, se presentan algunos problemas en la identificación de la ratio decidendi del precedente. En cuarto lugar, se analizan algunas de las distintas operaciones que se pueden realizar con un precedente. Por último se proponen algunas conclusiones provisionales.

Palabras clave: precedente, ratio decidendi, stare decisis, obligatoriedad, inducción.

\section{Without precedents: A skeptical look to «stare decisis» rule}

ABSTRACT: This paper aims to demonstrate how while a system without any precedent rule is dysfunctional, thus identifying its ratio decidendi as well as their conditions of application are highly indeterminate. To demonstrate this thesis we proceed through four steps. First, we try to clarify the concept of precedent, adopting a broad concept, and analyzing in what way those can be binding. Secondly, the question about when can we say that a legal system contains a binding rule of precedent arises. Thirdly, some problems in identifying the precedent ratio decidendi are addressed. Fourth, some of the various operations that can be performed with a precedent are analyzed. Finally some tentative conclusions are proposed.

Keywords: precedent, ratio decidendi, stare decisis, normativity, induction.

* Fecha de recepción: 2 de diciembre de 2014. Fecha de aceptación: 30 de junio de 2015.

Profesor de Introducción al Derecho de la Universidad Austral de Chile. Este trabajo se enmarca en mi proyecto Fondecyt «Realismo jurídico e indeterminación del derecho» (núm. 11130311) concedido por el Conicyt chileno. Agradezco a los participantes en el Seminario Austral de Derecho y en el Seminario de Teoría del Derecho de Vaquerías de la Universidad Nacional de Córdoba por sus comentarios. También debo agradecer a Daniela ACCATINO por sus comentarios, y a mis asistentes Paz MORA y Carla IUSPa por sus sugerencias para mejorar y reducir este trabajo. 


\section{INTRODUCCIÓN}

l objetivo del presente trabajo es mostrar cómo, pese a las dificultades para establecer qué es un precedente y cuáles son las partes vinculantes del mismo, es difícil imaginar un ordenamiento en el que no exista, al menos con un algún mínimo grado de vinculatoriedad, una norma sobre el precedente vinculante (regla del stare decisis). No obstante, la identificación de cómo ha sido decidido el caso puede resultar, y de hecho frecuentemente resulta, endiablada o sencillamente imposible.

Pretendo llegar a esta paradójica conclusión mediante los siguientes cuatro pasos. En primer lugar, intentaré aclarar la noción de precedente, y otras aledañas como ratio decidendi. En segundo lugar, trataré de establecer bajo qué criterios podemos afirmar que existe una regla sobre el precedente en un ordenamiento jurídico. En tercer lugar, me ocuparé de los problemas relativos a la identificación del precedente. En cuarto lugar, trataré de identificar qué podemos hacer con un precedente. Finalizaré con algunas conclusiones provisionales.

\section{QUÉ ES UN PRECEDENTE}

El primer problema que debemos abordar para poder avanzar en nuestro objetivo es el esclarecimiento de la noción de «precedente». Sin embargo, la revisión del concepto de precedente nos llevará también a revisar qué parte de las decisiones jurisdiccionales y en qué sentido pueden ser vinculantes.

\subsection{Una noción amplia de precedente}

En la literatura más extendida sobre los precedentes, se define aquellos como decisiones judiciales pasadas vinculantes que obligarían al mismo u otros órganos a decidir casos similares de la misma manera: «Hablamos de precedente judicial cuando una decisión de un tribunal constituye una autoridad obligatoria para el mismo tribunal y para otros de igual o inferior rango»; «[D]ecisiones tomadas previamente por otro tribunales que resolvieron un problema semejante»; «El problema de la vinculatoriedad de la doctrina judicial se unió desde el principio a la enumeración de las fuentes del derecho $[. .$.$] aunque nunca faltaron quienes, como PUIG BRUTAU, defendieran líneas muy$ proclives al precedente» ${ }^{1}$. Esta es, por decirlo así, la noción estándar de «precedente» ${ }^{2}$.

Sin embargo, dicha definición de «precedente» es, por un lado, reductiva y, por el otro, imprecisa, desde tres puntos de vista. En primer lugar, una definición como esta excluye del análisis otras decisiones judiciales diferentes de la sentencia a las que, de hecho, se le atribuye valor de precedente. En segundo lugar, una definición como esta

1 Cfr. ItURRALDE, 2014: 195; LegarRe y RiverA, 2006: 109; LAPORTA, 1997: 268.

2 Es preciso señalar como si bien muchas definiciones de «precedente» no hacen referencia intensionalmente a las decisiones judiciales, la práctica totalidad, y salvo expresa referencia en contrario, versan extensionalmente sobre el papel de decisiones judiciales pasadas en futuras decisiones judiciales. 
excluye del análisis las decisiones de otros órganos que califican jurídicamente casos genéricos o individuales pero que no calificaríamos como órganos judiciales en sentido estricto. Por último, esta definición resulta algo oscura o vaga en la medida en que la noción de «decisión pasada» puede excluir del análisis decisiones a las que puede ser discutible o extraño calificar como pasadas.

La visión tradicional acerca del precedente es reductiva porque excluye del análisis, en primer lugar, todas aquellas decisiones judiciales (o provenientes del órgano judicial) previas o incidentales que emanan los tribunales, que resuelven algún caso (genérico o individual), pero diferentes de la sentencia judicial ${ }^{3}$. Es decir, excluye un buen número de decisiones —admisiones a trámite, pronunciamientos incidentales, etc.- - que no son sentencias judiciales en sentido estricto pero que resuelven controversias sin entrar en el fondo de la cuestión.

En segundo lugar, la noción tradicional de «precedente» excluye del análisis también las decisiones de órganos que no pertenecen en sentido estricto al poder judicial pero que funcionan, o pueden funcionar, como precedentes. Es decir, la noción estándar de precedente presupone una visión excesivamente formalista de «jurisdicción» $\mathrm{o}$ de «órgano jurisdiccional», con el resultado de dejar fuera del análisis el posible valor vinculante de decisiones que resuelven casos genéricos o individuales y a los que el ordenamiento les concede (algún) valor jurídico. Por ejemplo: las decisiones de los órganos consultivos, de toda la Administración pública (DíEz SASTRE, 2008), de los órganos administrativos de las Cámaras electivas (LuPO, 2014), etcétera.

Por último, la noción estándar de «precedente» de la que hemos partido — como decisión judicial pasada vinculante- tiene, por último, el problema de incluir una dimensión temporal que, contra lo que pudiera inicialmente parecer ${ }^{4}$, es bastante engañosa: en primer lugar, por vaga y, en segundo, por estar basada en una asunción falsa.

Evidentemente, una decisión judicial pasada es la candidata ideal para convertirse en precedente vinculante. Ahora bien, se trata de una propiedad imprecisa, ya que no es en absoluto claro a partir de qué momento una decisión adquiere valor vinculante para otras decisiones. ¿Puede tener valor vinculante hacia otros órganos una decisión jurisdiccional recurrida?, ¿y hacia sí misma? ¿En qué momento una decisión se convierte en vinculante?

En segundo lugar, se trata de una propiedad —el hecho de que sea pasada- que está basada en asunciones falsas. En efecto, algunos autores han insistido en que la regla del auto-precedente, antes que un valor hacia el pasado, tendrían fuerza normativa hacia el futuro en la medida en que obliga al órgano a resolver la controversia mediante una norma universalizable, aplicable también a casos similares en el futuro ${ }^{5}$.

${ }^{3}$ Hay que añadir que, según algunos autores, podrían constituir precedentes únicamente las decisiones de algunos tribunales; en concreto, aquellos que están situados más arriba en la organización judicial de un sistema jurídico. No obstante, parece que se trata claramente de una cuestión puramente contingente, que puede cambiar en cada ordenamiento. Vid. para esta tesis GASCÓN, 1993: 11. A este respecto, vid., por ejemplo, el análisis de CROSS sobre el precedente en el sistema inglés, CROSS y HARRIS, 2012: 129 y ss.

${ }^{4}$ Es frecuente que se dé por buena y aproblemática dicha dimensión temporal de los precedentes. Vid. por ejemplo, CHIASSSONI, 2012: 214 y ss.; L. MORAL SORIANO, 2002: 127, 129.

${ }_{5}$ Este aspecto es tratado por SCHAUER, 1987. Lo que sostiene este autor es que cuando un órgano jurisdiccional sabe que su decisión será considerada como precedente, será mucho más cuidadoso al tomar y 
No solo sino que también es posible (y plausible) preguntarse si una decisión judicial que todavía no ha sido dictada puede resultar vinculante. Por extraño que pueda parecer, se encuentran algunos buenos y conocidos ejemplos de este fenómeno. Este sería el caso, por ejemplo, de las cuestiones incidentales de constitucionalidad presentes en algunos ordenamientos (como casi todos los europeos) o la cuestión prejudicial comunitaria en el ámbito de la $\mathrm{UE}^{6}$. Otro ejemplo: cuando un órgano debe juzgar un caso sustancialmente idéntico a otro ya decidido por sí mismo pero que ha sido recurrido, ¿debe esperar a la resolución del recurso contra su decisión anterior?

Para solucionar los anteriores defectos, es conveniente partir adoptando una noción amplia de «precedente». Con el fin de no limitar a priori el objeto de estudio, por un lado, es preciso adoptar una noción lo más amplia posible de jurisdicción y de decisión judicial y, por el otro, es preciso excluir consideraciones de tipo temporal pues, como hemos visto, es posible que, en cierto sentido, una decisión judicial sea vinculante incluso antes de ser dictada. Por tanto, por «precedente» entenderé aquellas decisiones jurisdiccionales que resuelven algún caso genérico o individual, y a las que se les reconoce eficacia no únicamente inter partes.

\subsection{Qué es vinculante del precedente}

Una vez que hemos identificado cuáles son las posibles decisiones candidatas a ser precedentes vinculantes (decisiones jurisdiccionales que, en algún sentido, se convierten en obligatorias para otras decisiones respecto de otros casos similares), podemos preguntarnos qué es, dentro de toda la decisión jurisdiccional, aquello vinculante para resolver otros casos similares.

\subsubsection{Obiter dicta $y$ ratio decidendi}

Cuando nos preguntamos sobre qué es un precedente, e identificamos algunas decisiones jurisdiccionales como vinculantes, la pregunta que surge inmediatamente a continuación es qué parte exactamente de la decisión jurisdiccional es la que puede

elaborar su decisión. La cuestión no es menor porque el tribunal puede modificar su decisión si sabe que en el futuro no tendrá el mismo margen de discrecionalidad para decidir. Por ejemplo, es posible que la decisión haga referencia a categorías más o menos generales y abstractas, por lo que el precedente afectaría hacia el futuro a un mayor o menor grupo de casos. Cuando los tribunales son conscientes de este aspecto, entonces racionalmente tenderán a tomar en cuenta dicha situación para fallar el caso actual.

Por su parte, señala Marina GASCÓN en relación al autoprecedente que «aunque los casos sustancialmente idénticos resueltos por un mismo tribunal con posterioridad a la resolución impugnada no sean en principio válidos «como término de comparación», sí que sirve para comprobar si la decisión impugnada [...] es una decisión con carácter genérico o no, en la medida en que haber resuelto casos posteriores a la decisión divergente conforme al criterio interpretativo anterior a la misma parece un claro indicio de su naturaleza voluntarista y arbitraria». Cfr. GASCÓN, 1993: 101. En términos similares PRIETO SANCHís, 1991: 188 y ss. Vid. también, WALDRON, 2012.

${ }^{6}$ OrOZCO MuÑoz, 2011: 183 y 245 y ss. No obstante, es preciso señalar que cuando el autor define la noción de precedente, afirma que se trata de una decisión jurisdiccional pasada. Sin embargo, el mismo autor admite que en la práctica jurisdiccional española y de la Unión Europea se concede eficacia a los precedentes de forma inmediata, incluso para procesos ya iniciados o, incluso, recurridos. Cfr. OROZCO MUÑOZ, 2011: 185 y 224-226. 
resultar, en algún sentido aún por precisar, vinculante. Tradicionalmente ha venido considerándose que no es toda la decisión jurisdiccional en su conjunto la que resulta vinculante, sino solo una parte.

En este orden de cosas, suele distinguirse entre obiter dicta y ratio decidendi. En síntesis, aquello que sería vinculante de la decisión jurisdiccional sería la ratio decidendi, considerándose el resto obiter dicta sin valor vinculante ${ }^{7}$. Ambos conceptos constituirían, al menos prima facie ${ }^{8}$, una división exhaustiva y excluyente, siendo suficiente definir uno de ellos para delimitar el otro.

No obstante, por ratio decidendi es posible entender, al menos, tres cosas diferentes $^{9}:$ a) la norma general aplicada en la decisión; $b$ ) la norma general, más el conjunto de hechos del caso; c) todos los elementos esenciales o necesarios para la decisión judicial.

Aquí, por razones conceptuales, descartaré el segundo criterio de distinción, limitando el análisis al primero y al último. Ello, en primer lugar, porque la segunda noción de ratio decidendi parece una subclase de la tercera. En segundo, porque quienes consideran que los hechos considerados relevantes en la decisión forman parte de la ratio decidendi parecen presuponer que habría una sola norma que, a la luz de los hechos del caso, justificaría la decisión judicial (lo que, como veremos más adelante, resulta erróneo) ${ }^{10}$ (infra 4.3).

i. Según el primer concepto, la ratio decidendi sería únicamente la premisa mayor del silogismo deductivo (práctico) que ha seguido el juez para llegar a la decisión, siendo el resto de la decisión obiter dicta. Es decir, lo único que resultaría vinculante es la norma que se ha aplicado en la decisión jurisdiccional: aquello que hace que la decisión esté justificada a la luz de los hechos considerados probados relevantes.

ii. Según el segundo criterio de distinción, ratio decidendi no sería únicamente la norma general que ha funcionado como premisa mayor del silogismo práctico sino todo el conjunto de consideraciones necesarias que ha realizado el juez para alcanzar y justificar su decisión.

Ambas nociones de ratio decidendi tienen, respectivamente, sus ventajas e inconvenientes.

${ }^{7}$ Hay que llamar la atención de que se han ofrecido diferentes definiciones de obiter dicta, entre las cuales encontramos aquella que lo define como el conjunto de las decisiones que forman parte de la justificación externa (diferentes, por tanto, de la premisa mayor del silogismo judicial) pero que son lógicamente necesarias para la regla del caso. Pero, además, es frecuentemente admitido que algunos obiter dicta, de hecho, tienen un valor persuasivo. Vid. CROSS y HARRIS, 2012, 101.

${ }^{8}$ Prima facie porque algunos autores consideran que entre ratio y obiter dicta habría que colocar aquellos dictum que tienen un gran peso persuasivo. Sin embargo, si «persuasivo» quiere decir vinculante en algún sentido, estos dictum serían en realidad parte de la ratio decidendi.

Lo que demuestra esta controversia es que en realidad se manejan dos nociones diferentes de ratio decidendi: la primera de ellas es de carácter estructural, e identificaría la ratio decidendi con alguna parte de la sentencia (éste es el concepto que hemos asumido aquí y del que cabe distinguir tres concepciones); la segunda tiene carácter normativo y se refiere a aquella parte de la sentencia que despliega efectos jurídicos no solo inter partes. Es decir, un primer concepto estructural (una parte de la decisión) y otro normativo (aquello que es vinculante).

9 Sigo aquí Igartua, 2006. Pero vid. también ChIASSONI, 2012: 222 y ss., ItURRALDE, 2014: 195, y SHINER, 2014.

10 Schauer, 2013: 65. Vid. también, Cross y Harris, 2012: 82. 
i. El primer criterio para distinguir entre obiter dicta y ratio decidendi tiene la ventaja de que establece una frontera, al menos desde el punto de vista conceptual, nítida entre ambos: cualquier tipo de consideración o razonamiento acerca de las razones por las que el órgano jurisdiccional ha alcanzado la decisión son sencillamente irrelevantes (obiter dicta), siendo únicamente vinculante la premisa mayor de la decisión. Sin embargo, pese a su nitidez, esta forma de distinguir ratio decidendi de obiter dicta tiene algunos inconvenientes.

El problema fundamental es que parece que hay partes de la decisión judicial, diferentes a la norma que sirve como premisa del silogismo judicial, que pueden tener - y de hecho tienen- algún valor vinculante. Si bien cabría incluir algunas de dichas decisiones - ampliando la noción de ratio decidendi hasta incluir cada uno de los silogismos deductivos que compondrían la decisión ${ }^{11}$ — lo cierto es que esta forma de entender el precedente excluye la atribución de valor vinculante al menos a algunas de las razones por las que la decisión estaría externamente justificada. Excluiría, por ejemplo, las decisiones interpretativas (por ejemplo, acerca de qué criterio interpretativos aplicar) alcanzadas por los tribunales y sobre las que cabe poca duda que se les atribuye valor de precedente vinculante; o, otro ejemplo, resultaría vinculante el producto de una ponderación entre principios, pero no las consideraciones no subsuntivas que ha realizado el órgano para alcanzar tal ponderación producto; o, finalmente, los juicios de valoración judicial de la prueba ${ }^{12}$.

ii. El segundo criterio de distinción permite considerar como vinculante también las razones aducidas por el órgano jurisdiccional para justificar su decisión. Ahora bien, el segundo criterio no resulta menos problemático: ¿cuáles son el conjunto de todas las consideraciones que debemos considerar como «necesarias»? ¿todas aquellas cuya modificación implicarían un cambio de la decisión final? Establecer cuáles son las consideraciones necesarias de la decisión genera no pocos problemas.

En primer lugar, desde el punto de vista empírico, no resulta muy plausible afirmar que son todas y cada una de las razones que forman parte de la justificación externa de la sentencia las que resultan vinculantes. De hecho, es perfectamente posible pensar en una decisión que se considere vinculante, por ejemplo, respecto a cómo se ha decidido el fondo pero no respecto a los argumentos procesales, pero también al revés. Y, claro está, una modificación de alguna de las decisiones podría haber modificado la decisión final del tribunal.

En segundo lugar, desde un punto de vista conceptual, incluso aunque admitamos que las razones aducidas por el tribunal son también vinculantes, resulta extremadamente complicado determinar cuáles de ellas son necesarias en casos de que haya

${ }^{11}$ Hay que tener en cuenta que, si concebimos la decisión judicial como un conjunto de decisiones que se van sucediendo (al menos desde un punto de vista formal) lógicamente, ratio decidendi podría ser considerado gran parte del razonamiento. Es decir, todas aquellas decisiones que constituyen operaciones de tipo subsuntivo podrían ser parte de la ratio decidendi. Lo que quedaría fuera es precisamente todas aquellas operaciones llevadas a cabo por el órgano jurisdiccional que no pueden ser consideradas como subsuntivas como, por ejemplos, los juicios ponderativos, la concreción de principios, la apreciación de la prueba, la satisfacción del estándar de prueba, etcétera.

${ }_{12}$ Sobre los precedentes en materia de hechos en la Corte Suprema estadounidense, puede verse LARSEN, 2013. 
varias rationes decidendi ${ }^{13}$. Por un lado, porque muchas decisiones judiciales están fundamentadas en términos de razones contribuyentes concurrentes, no individualmente concluyentes. Por el otro, incluso aunque sean formuladas en términos de razones concluyentes, podría darse el caso de que los argumentos fueran suficientes pero no necesarios para la justificación de la sentencia, es decir, para los casos con varias rationes decidendi alternativas todas ellas suficientes para justificar la decisión.

\subsubsection{Reglas y casos paradigmáticos}

Algunos autores, como Frederick SCHAUER, han sostenido que existiría una diferencia cualitativa entre el papel que cumplen los precedentes y el razonamiento por analogía en el razonamiento judicial. Aunque de manera no del todo clara (VeLuZZI, 2011: 108.), parece que la distinción establecida por SCHAUER pasa por afirmar que los órganos jurisdiccionales no tendrían libertad para seguir o no el precedente, mientras que sí la tendrían para seguir o no un razonamiento por analogía (SCHAUER, 2007: 1-21). O, dicho de otro modo, mientras que el precedente incorporaría una razón protegida de segundo orden para decidir el caso de una determinada manera, este no sería el caso del razonamiento por analogía (que constituiría una razón de primer orden dependiente del contenido para decidir un caso). Por supuesto, aquí la noción de autoridad de RAZ parece llamada a jugar un papel fundamental ${ }^{14}$.

Ahora bien, esta forma de distinguir entre analogía y precedente tiene el problema de excluir la posibilidad de que un precedente no goce de una especial protección dentro del ordenamiento en razón de su fuente pero que, sin embargo, sea vinculante de algún modo. De hecho, este parece ser precisamente el caso de los precedentes con valor meramente persuasivo, bastante frecuentes en los países de tradición de civil law, en los que muchas veces ni siquiera existen normas explícitas sobre el precedente (o son de prohibición).

Antes que dos formas heterogéneas de razonar, la distinción trazada por SCHAUER entre analogía y precedente parece servir más bien para configurar dos formas diferentes de concebir los precedentes. El problema, o la confusión, nace de que, mientras que el discurso del precedente hace referencia al uso por parte de tribunales de reglas en decisiones anteriores, aquel de la analogía versa sobre una forma de razonar (y no de la fuente del material argumentativo). Parece pues que no es posible distinguir razonamiento por analogía y uso de precedente como dos clases dentro de una misma familia, sencillamente porque son conceptos modelados sobre criterios heterogéneos: tipo de razonamiento el primero, uso de un contenido proposicional en función prescriptiva por razón de su origen el segundo.

En este sentido, las dos formas de concebir la diferencia entre obiter dicta y ratio decidendi analizadas en el parágrafo anterior parecen ser el reflejo de estas dos formas

${ }_{13}$ Esto es a lo que parece referirse Cross e, indirectamente, WAmbaugh cuando afirman que el test del último, sirve solo para los casos en los que «el caso versa sobre un único punto». CROSS y HARRIS, 2012: 77.

${ }_{14}$ Sin embargo, el propio RAz parece dudar sobre que los precedentes entendidos como reglas tengan la misma autoridad que las reglas provenientes del legislativo. Esto parecería indicar la revisión, en términos graduales, de la noción de autoridad. DUXBURY, 2008: 104 y ss. 
de concebir los precedentes y su uso: como una regla aplicada por un tribunal (sujeta a las reglas de la lógica de normas de condicional cerrado ${ }^{15}$ ), o como un caso paradigmático ${ }^{16}$ (sujeto a las reglas del razonamiento por analogía ${ }^{17}$ ).

Desde el primer punto de vista, el precedente sería una regla de carácter —más o menos- general y abstracto, cuya aplicabilidad, en principio, no dependería de nada más que de la constatación, en el caso a juzgar, de las propiedades previstas en el antecedente de la norma. La ratio decidendi, desde este primer punto de vista, sería sencillamente el conjunto de propiedades que han sido consideradas como relevantes en la norma aplicada más su calificación deóntica. De este modo, si concebimos el precedente como regla, regirá el refuerzo del antecedente (al menos prima facie), resultando el resto de consideraciones irrelevantes en lo que se refiere a su aplicabilidad interna.

Desde el segundo punto de vista, el precedente sería un caso paradigmático, es decir, un ejemplo excelente de cómo se debe solucionar un tipo de caso, pero que padece de vaguedad combinatoria o prevé entre las propiedades de su antecedente propiedades valorativas. Es desde este punto de vista desde el que resulta plausible afirmar que la ratio decidendi está compuesta por el conjunto de todas las razones esenciales o necesarias para el fallo ${ }^{18}$.

Cuándo deba considerarse que un precedente expresa una regla o un caso paradigmático es cuestión que depende completamente de las concepciones teórico-jurídicas del intérprete. Dicho de otro modo: es una cuestión de preferencias, no pudiendo establecerse ningún criterio jurídico de carácter objetivo que permita determinar objetivamente ante qué tipo de precedente estamos ${ }^{19}$. En este sentido, parece que son las sucesivas elaboraciones y reelaboraciones de dogmática y jurisprudencia las que determinan tanto su naturaleza como el cambio de aquellas. Es decir, el precedente puede ser reformulado, y son de hechos reformulados, a través de sucesivos usos, pasando

15 Podría argüirse que es perfectamente posible establecer una analogía legis con base en una regla. Esto está fuera de discusión. Sin embargo, en el momento en que nos preguntamos por la extensión analógica de la regla lo que estamos haciendo es entrar a valorar si las nuevas condiciones del caso a decidir son suficientes para la creación de tal regla. Y, en este sentido, parece que para valorar la oportunidad de la operación estamos convirtiéndolo en un caso paradigmático.

16 Por regla, en este contexto, estoy entendiendo aquella norma que tiene un condicional cerrado y cuyas condiciones de aplicabilidad interna no padecen de vaguedad combinatoria, y que no tiene entre sus propiedades elementos de contenido moral. Por caso paradigmático, por el contrario, entiendo en este contexto aquel caso ejemplificativo en el que se aplica una norma cuyas condiciones de aplicabilidad no están identificadas exhaustivamente, esto es, desconocemos cuáles son todas las propiedades relevantes y/o desconocemos si son necesarias, suficientes y/o contribuyentes. A ello habría que añadir la presencia en el antecedente de la regla de alguna propiedad de contenido moral.

17 Ésta es también la doble forma en la que Jerzy WROBLEWSKI concibe los precedentes. Sin embargo, este autor los considera como mecanismos de motivación o formas de usar el precedente. Sin embargo, el mismo autor afirma que en todo caso «es necesario [con todo] establecer con certeza que el caso a considerar y el que ha sido objeto de la decisión precedente son similares en puntos esenciales». Sin embargo, cuando concebimos el precedente como una regla esto no es necesario sino que basta con que las propiedades consideradas como relevantes en la norma que constituye la ratio decidendi del precedente sean constatadas en el caso a decidir, no siendo necesaria ninguna consideración ulterior. Vid., WROBLEWSKI, 2008: 312.

18 De manera parecida, Jerome FRANK configuró los precedentes como metáforas en el sentido de que se trataba de buenos ejemplos sobre cómo solucionar un tipo de caso pero que debían servir solo y únicamente como punto de partida. Vid. FrANK, 1953: 71-72.

19 Wroblewski considera que estas dos formas de motivar con base en el precedente «pueden convertirse la una en la otra». WROBLEWSKI, 2008: 301. 
de ser considerado inicialmente un caso paradigmático a ser una regla, pero también al revés ${ }^{20}$.

\subsection{Grados de vinculatoriedad del precedente}

El tema de la vinculatoriedad del precedente ha sido uno sobre los que más se ha discutido en los últimos decenios al calor de reformas procesales, planteándose la posibilidad de establecer algún grado de vinculatoriedad para las decisiones jurisdiccionales. En estos debates, los detractores del precedente han argüido frecuentemente que su implantación implicaría una violación de la separación de poderes (y/o un gran margen de discrecionalidad judicial). Los jueces, se afirma, están o deben estar únicamente sujetos a la ley, y a nada más.

No han sido pocos quienes, al calor de dichas discusiones, han cuestionado la justificación de tales alarmas debido a que los detractores del precedente habrían dado por descontado su máximo grado de vinculatoriedad lo que, en realidad, sería solo una posibilidad conceptual ${ }^{21}$ (y, por lo demás, posibilidad que no se constataría en ningún ordenamiento $)^{22}$. En este sentido, la literatura teórico-jurídica viene distinguiendo en los últimos decenios entre diferentes grados de vinculatoriedad ${ }^{23}$.

Aquí no intentaré presentar una lista de los diferentes grados en los que la regla del precedente puede ser vinculante ${ }^{24}$. No se trata, no obstante, de que la regla del precedente sea, como parecen afirmar algunos autores ${ }^{25}$, gradual, pudiendo obedecerse poco o mucho (al modo de los mandatos de optimización). Antes bien, lo que tenemos son diferentes conjuntos de reglas — que determinan diferentes sistemas- sobre el precedente que los órganos jurisdiccionales pueden cumplir o incumplir.

Para intentar distinguir entre los diferentes tipos de normas sobre el precedente y, por tanto, entre los diferentes grados en los que pueden ser vinculantes los precedentes, lo primero que tenemos que hacer es distinguir entre la propia regla del precedente (stare decisis) y cada una de las las decisiones que constituyen un precedente (rationes decidendi). Ello es importante, en primer lugar y como enseguida veremos, porque la observancia de la regla del stare decisis no implica necesariamente la aplicación de la ratio decidendi de un caso.

En segundo lugar, porque nos permite ver con mayor claridad que, cuando hablamos de regla del stare decisis no estamos hablando de una sola norma, sino de un intrincado conjunto de normas. Si bien la cuestión requeriría sin duda un mayor análisis, un sistema de precedente comprende, al menos, las siguientes normas: (1) una norma

20 SCHAUER, 1987: 574.

21 LAPORTA, 1997: 271. Vid. también ACCATINO. 2002.

22 Ni siquiera en el derecho inglés. Vid. R. Cross y HARris, 2012: 245 y ss.

23 Resulta en este sentido paradigmático el trabajo realizado por un grupo de teóricos del derecho y procesalistas acerca del precedente. N. MACORMICK y Summers, 1997: vii. Para una revisión crítica de aquellos, vid. CHIASSONI: 2012: 231 y ss.

24 Para una reconstrucción prácticamente exhaustiva de los grados en los que los que los precedentes pueden ser vinculantes, remito nuevamente a P. CHIASSONI, 2012.

25 Para el argumento contrario, MORAL SORIANO, 2002: 131. En los mismos términos los plantea BraVOHurTado, 2013: 568. 
que califica su uso institucional (permitido, obligatorio o prohibido); (2) una norma sobre qué acciones implican emplear un precedente por parte de un órgano jurisdiccional (mencionar, tener en cuenta o aplicar); (3) otra sobre el contexto justificativo en el que sería eficaz (res iudicata, interpretata, verificata); (4) una norma acerca de la fuerza justificativa de dicha norma (concluyente o contribuyente); y (5) una norma sobre el tipo de razón de segundo orden que incorpora (protegida o no protegida) ${ }^{26}$. Ello, insisto, sin la pretensión de realizar aquí un análisis exhaustivo ${ }^{27}$.

Para diferenciar entre cada uno de estos aspectos es preciso agrupar estas reglas bajo dos categorías. El primer grupo de normas sobre el precedente hace referencia a la obligación institucional que genera en los órganos jurisdiccionales la regla del stare decisis. El segundo grupo, por el contrario, hace referencia al papel justificativo de dichas razones.

\subsubsection{La dimensión institucional}

Esta primera dimensión hace referencia a las obligaciones que la norma del stare decisis genera para el órgano jurisdiccional, es decir, cuáles son las acciones que tienen que llevar a cabo los jueces para satisfacer la norma del precedente. Desde el punto de vista de las obligaciones institucionales del juez, es necesario distinguir entre dos aspectos: el comportamiento regulado y el carácter atribuido a aquel.

2.3.1.1. Respecto del carácter del comportamiento regulado, aquel puede ser calificado de diferentes maneras. a) Tendremos un carácter permitido toda vez que los jueces pueden usar precedentes jurisdiccionales, más allá de qué valor se le conceda a dicha referencia ${ }^{28}$. b) Tendremos un carácter prohibido toda vez que los jueces no pueden usar los precedentes en sus decisiones ${ }^{29}$. c) Por último, es posible que el uso jurisdiccional de precedentes pueda ser considerado como obligatorio (aunque esto no predetermina su peso).

2.3.1.2. Respecto del comportamiento regulado, en realidad estos pueden ser de lo más variados (por razones de sencillez, usaré como ejemplo el caso en el que el comportamiento es obligatorio). En primer lugar, aquello considerado obligatorio puede

${ }^{26}$ En un ordenamiento puede no haber normas explícitas sobre alguno o varios de estos aspectos, pero también carecer completamente de reglas explícitas sobre esta materia.

27 A estas habría que añadir, por ejemplo, otra norma de tipo conceptual acerca de qué decisiones tienen valor de precedente (la «regla de reconocimiento» de los precedentes). Suele darse por descontado que la identificación de qué decisiones jurisdiccionales cuentan como precedentes es una actividad poco problemática. Sin embargo, las cosas están lejos de ser así. Entre las propiedades que identifican qué decisiones cuentan como precedentes, es posible que se contemplen, entre otras, la reiteración de la decisión, qué se entiende por reiteración, qué órganos tienen competencia para dictar decisiones con valor de precedente, si las decisiones carentes de motivación tienen valor de precedente, quién puede derogar un precedente, etcétera.

28 Según CROSs, las sentencias 66/80 International Chemical Corporation SpA v. Amministrazione delle Finanze dello Stato y en 112/83 Societé des Produits des Mais SA v. Administration des Douanes et Droits Indirects, ambas del Tribunal de Justicia de las Comunidades Europeas, establecen la competencia de los tribunales nacionales para considerar como inválida una norma comunitaria si anteriormente ello había sido considerado de este modo por el Tribunal de Justicia. Es decir, el juez nacional podría fundar su decisión apoyándose en la decisión del TJCE, pero ello no era obligatorio. Cfr. CROss y HARRIS, 2012: 37, n. 24.

29 Esto abre la posibilidad no solo a que el uso de precedentes esté prohibido, sino a que existan precedentes negativos. Me reservo el argumento para otra ocasión. 
ser $a$ ) mencionar el precedente, $b$ ) tener en cuenta (como razón) el precedente, o bien c) usar el precedente ${ }^{30}$.

No obstante, la expresión «usar un precedente» puede adoptar diferentes significados. «Uso del precedente» puede significar al menos las siguientes cosas: $c 1$ ) usarlo como premisa mayor del razonamiento; $c 2$ ) usar como premisa mayor del razonamiento una norma que es consecuencia lógica de la norma expresada por el precedente; c3) usar como premisa del razonamiento una norma axiológicamente coherente con el precedente; $c 4$ ) usar como premisa del razonamiento una norma instrumentalmente coherente con los fines planteados por el precedente ${ }^{31}$.

\subsubsection{Dimensión justificativa del precedente}

La dimensión justificativa del precedente no es sino un corolario de las normas acerca de cuándo una decisión jurisdiccional está justificada. Sin embargo, es preciso distinguir entre dos aspectos implicados en esta dimensión justificativa.

2.3.2.1. El primer aspecto se refiere al momento o lugar de la justificación práctica en el que el precedente puede ser relevante. En este sentido, es posible distinguir entre: $a$ ) un precedente de solución (para referirnos tanto a la decisión final como a las soluciones intermedias ${ }^{32}$ de carácter subsuntivo que toma el juez); $b$ ) un precedente de interpretación (para referirnos no al uso de reglas interpretativas que tendrían un carácter subsuntivo sino directamente a interpretaciones-producto de determinadas disposiciones normativas); c) un precedente probatorio (para referirnos a aquella decisión de carácter no subsuntivo por la que un órgano considera suficientemente probado un hecho a partir de un determinado material probatorio).

2.3.2.2. El segundo aspecto se refiere al punto de vista de las razones para la acción. Aquí es preciso establecer dos diferencias: primero, según la fuerza justificativa de los mismos (concluyente o contribuyente); segundo, según su grado de protección.

Desde el primer punto de vista, a) tendremos un precedente con carácter concluyente cuando la mención de aquel constituye argumento suficiente para una decisión jurisdiccional ${ }^{33}$ (o una parte de aquella). b) Tendremos una razón contribuyente cuando el precedente no puede ser utilizado como único fundamento de la decisión (o de una parte de aquella) pero cuenta como argumento a su favor.

En segundo lugar, se suele considerar que los precedentes son razones protegidas ${ }^{34}$. Por «razón protegida» estoy entendiendo la especial consideración de la que go-

30 Vid., por ejemplo, CROSS y HARRIS, 2012: 24.

31 Formulo esta tipología a partir de una reconstrucción de una clasificación elaborada por CHIASSONI, 2012: 235 y ss.

32 Por ejemplo, imagínese que se discute sobre la posible indemnización por la finalización de una relación de trabajo con un empleado público, discutiéndose si para tal caso es aplicable la legislación laboral, administrativa o mercantil. En tal caso, tenemos al menos dos decisiones, dependiendo la segunda de la primera: la primera acerca de cuál es la legislación aplicable (laboral, administrativa o mercantil), la segunda relativa a la legalidad de tal indemnización con base en la decisión sobre qué normativa es la aplicable.

33 Esto, por supuesto, no obsta para que la decisión sea derrotable. Sobre esto, de nuevo remito a la exhaustiva tipología presentada por CHIASSSONI. Cfr. CHIASSONI, 2012: 235 y ss.

34 SCHAUER, 2007: 1-21. 
zan algunas razones en la justificación judicial por alguna razón diferente de aquella de primer orden que la propia ratio incorpora. Se trata, por tanto, de razones de segundo orden que protegen la norma expresada en la ratio decidendi, haciendo más difícil que aquella sea desplazada o derrotada.

Pues bien, no parece muy plausible sostener que todos los precedentes son siempre razones protegidas, o que esta es la única forma en la que podemos entender los precedentes. Ello precisamente por lo que se conoce como fuerza persuasiva de los precedentes ${ }^{35}$. En efecto, uno de los tipos de fuerza vinculante más frecuentemente identificada en la tradición del civil law ${ }^{36}$ es aquel en el que los precedentes no gozarían de una protección especial por parte de los ordenamientos pero tendrían una fuerte capacidad de convicción ${ }^{37}$. Es posible, en este sentido, distinguir entre precedentes que incorporan una razón de segundo orden que los otorga una especial deferencia, y precedentes que no gozan de tal consideración. Huelga añadir que dicha protección puede tener diferentes grados, siendo su máximo grado — pero no el único posible- que el precedente incorpore una razón excluyente de segundo orden.

\section{CUÁNDO EXISTE LA REGLA DEL PRECEDENTE}

Lo que me interesa discutir en esta sección son las condiciones para poder afirmar que en un ordenamiento existe o no una regla - mejor dicho, un sistema- del precedente vinculante. Para alcanzar tal objetivo, en primer lugar, analizaré por qué, si bien se trata de una cuestión contingente, es difícil imaginar un ordenamiento en el que no exista ninguna regla del precedente. En segundo lugar, distinguiré entre cuatro formas en las que la regla del precedente puede formar parte de un ordenamiento.

\subsection{La necesidad funcional de la regla del precedente}

Según Michel TROPER, pese a la prohibición expresa de la regla del precedente en el Código Civil francés — por lo demás, justificada en la división de poderes- en tal ordenamiento existiría una regla del precedente vinculante (TROPER ,1996). Ello pese a que el sistema francés contendría dos prohibiciones explícitas de dotar de eficacia erga omnes a las decisiones jurisdiccionales: en primer lugar, una prohibición de carácter general dirigida a los jueces de formular normas de carácter general tanto en el fallo como en la justificación de la decisión; en segundo lugar, la obligación de fundar sus

35 La persuasividad de facto no es una propiedad que haga referencia a la fuerza del precedente sino, por el contrario, al grado de protección que gozan los precedentes. Desde luego, protección y vinculatoriedad son propiedades relacionadas pero que no deben ser confundidas. Basta, en este sentido, con imaginar una razón persuasiva de facto que funcione como razón concluyente, o bien una razón protegida que, sin embargo, tiene asignado un valor únicamente contribuyente en una decisión. Este punto es ilustrado por Jerzy WROBLEWSKI cuando indica que un precedente no puede ser usado, en algunos ordenamientos, como única razón para decidir un caso. Cfr. WROBLEWSKI, 2008: 308.

36 Producto de dicha reunión fue el conocido volumen de MACORMicK y SuMmers, 1997.

37 Para una crítica de precedente persuasivo de facto, vid. CHIASSONI, 2012: 234. 
fallos únicamente en la ley, y la especular prohibición de justificar las decisiones únicamente en otras decisiones jurisdiccionales ${ }^{38}$.

Pues bien, según TROPER, pese a que el legislador francés ha tratado de evitar un sistema de precedentes, el resultado habría sido exactamente el contrario. Y, se podría añadir, no podía ser de otro modo, debido a dos factores: en primer lugar, otras previsiones normativas que parecían contribuir a concluir exactamente lo contrario; y, en segundo lugar, una serie de factores «funcionales» que hacen que sea difícilmente posible la no existencia de algún tipo de regla sobre el precedente.

a) En relación con otras previsiones normativas, el surgimiento del precedente en Francia se debe a dos disposiciones: por un lado, el art. 4 del Código Civil francés que califica como denegación de justicia la negativa a pronunciarse por parte de los jueces (prohibición de non liquet); por el otro, la instauración de un órgano dedicado a controlar la correcta aplicación de la ley por parte de los tribunales ${ }^{39}$.

Respecto a la prohibición de non liquet, a decir verdad, aquella no genera de por sí un sistema de precedente: únicamente obliga a los jueces a formular normas de carácter general para decidir las controversias para las que surge una laguna. Sin embargo, no parece implicar que las normas formuladas por los jueces puedan ser aplicables y/o tengan eficacia erga omnes. Esto es, la obligación de decidir implica solo la imposibilidad de satisfacer simultáneamente la prohibición de no formular normas generales de decidir tales casos, pero no implica de por sí un sistema de precedentes ya que tales normas podrían tener eficacia únicamente inter partes.

Respecto a la instauración de un órgano de casación, se podría discutir si la instauración de un tribunal dedicado al control de la (correcta) aplicación de la ley es base suficiente para afirmar que existe una regla del precedente (vertical) vinculante. En efecto, se podría sostener que lo único que controla un tribunal de casación es que el derecho se aplique «correctamente».

Sin embargo, tal visión se basa en una percepción formalista y algo ingenua sobre lo que supone la aplicación del derecho en general, y la interpretación judicial en particular. No solo porque supone, en este sentido, que el derecho admite una sola interpretación. El problema es que, más allá de que exista una sola interpretación correcta, incluso aunque esta tesis fuera verdadera (lo que es más que discutible), los desacuerdos sobre cuál es la interpretación correcta de hecho se producen, y los órganos de casación emiten normas sobre cómo interpretar tales enunciados.

Resulta pues muy poco plausible pensar que los tribunales de casación se dedican únicamente a velar por la buena aplicación del derecho. Antes bien, dichos tribunales establecen una como la interpretación vinculante del derecho, formulando de este modo meta-reglas interpretativas, a veces de carácter sumamente general.

En definitiva, incluso allí donde parece haber una normativa contraria a la regla del stare decisis, surgen en la práctica instituciones que juegan un papel similar,

38 TROPER, 1996: 65 y ss. Para un brevísimo resumen histórico acerca de cómo la regulación de los precedentes en el Código Civil napoleónico influyó, de manera análoga, en el ordenamiento jurídico español, vid. LAPORTA, 2009:, 12 y ss.

39 Ley de la Asamblea Nacional Francesa del 16-24 de septiembre 1791, título VIII, art. 23. 
cuando no completamente equivalente, a la regla del precedente. Y es que resulta francamente complicado encontrar algún ordenamiento en el que la regla del stare decisis no goce de algún tipo de reconocimiento, por escaso que sea este. Veamos las razones.

b) Son factores — que a falta de nombre mejor llamaré- de «carácter funcional» los que hacen difícil imaginar un ordenamiento jurídico en el que no exista algún tipo de regla sobre el precedente. Aunque no es este el lugar indicado para analizarlo, creo que resulta pacífico sostener que en los ordenamientos jurídicos de nuestro entorno se producen casos de indeterminación ${ }^{40} \mathrm{o}$, al menos, que los jueces deciden de maneras diferentes (más allá de que se equivoquen o no, y con qué frecuencia se produzca). Pues bien, si así están y los jueces tienen en ocasiones posibilidad de decidir los casos de distintas maneras (aunque sea solo que efectivamente puedan hacerlo y así lo hagan), es más que razonable pensar que los jueces toman en cuenta otras decisiones jurisdiccionales sobre casos similares (aunque sea, al menos, por razones de economía en la toma de decisiones).

Es posible afirmar que un ordenamiento jurídico que no tiene ningún tipo de regla del precedente funciona mal, desde dos puntos de vista.

En primer lugar, un ordenamiento en el que no hay ningún tipo de regla del stare decisis ve aumentado su nivel de incertidumbre. Si existe un alto grado de incertidumbre acerca de lo que exige el derecho, entonces aquel difícilmente servirá para orientar el comportamiento. Dicho de otro modo, no podrá satisfacer su función principal que es orientar el comportamiento de los ciudadanos (ni, en realidad, tampoco el de los jueces). Y, se podría concluir, si el nivel de incertidumbre fuera demasiado alto, no reconoceríamos aquel como un ordenamiento jurídico porque no serviría para orientar la conducta.

En segundo lugar, en un ordenamiento sin algún tipo de regla del stare decisis se aumenta ostensiblemente los costos de la decisión y justificación jurisdiccional. En síntesis: es ineficiente volver a discutir una cuestión cada vez que se presenta en la práctica si aquella ha sido decidida previamente (RAZ, 1985: 146). Cuando los jueces tienen la obligación de decidir los casos similares del mismo modo a como se ha hecho en el pasado, se dota al razonamiento judicial de un criterio de autoridad suplementario, lo que - al menos prima facie - tiende a aumentar la determinación normativa en tal ordenamiento, y a reducir los costos de decisión (y de justificación) (OROZCO MUÑOZ, 2011: 236 y ss.).

No obstante, es preciso subrayar que es perfectamente posible un ordenamiento en el que no exista una regla del stare decisis. Lo que estoy sosteniendo no es, por tanto, que no existan o no puedan existir lógicamente ordenamientos sin algún tipo de regla del precedente. Lo que sostengo, por el contrario, es que en la mayoría de ordenamientos efectivamente existe alguna regla del stare decisis, técnica usada frecuentemente como instrumento para reducir la incertidumbre y aumentar la eficiencia en la toma de decisiones, incluso contra legem.

40 Sobre la indeterminación racional del derecho me permito remitir a NúÑEZ VAQUERO, 2013. 


\subsection{Formas de «existencia» de la regla del precedente}

En el presente apartado voy a tratar de establecer bajo qué condiciones podemos decir que hay, dentro de un ordenamiento jurídico, una regla del stare decisis. Por razones que no es posible explicitar, aquí no seguiré la aproximación tradicional a este problema que, sobre todo en la cultura jurídica del civil law, presenta este como un problema acerca de las fuentes del derecho (especialmente las formales).

Aquí, por el contrario, voy a adoptar un punto de vista diferente basado en la idea de la validez (entendida como pertenencia) de una regla del stare decisis. Pues bien, cuando nos preguntamos si en un ordenamiento existe una regla del stare decisis lo que hacemos es preguntarnos por las condiciones de validez de una norma dentro de un sistema jurídico. Es precisamente esta la perspectiva que asumiré aquí.

Hoy en día es poco discutido que una norma puede pertenecer a un ordenamiento jurídico de diferentes maneras o a diferente título (CARACCIOLO, 1988). Puede, en primer lugar, pertenecer en cuanto norma derivada del ordenamiento, es decir, en cuanto norma que ha sido emanada por una autoridad competente y que no contradice normas jerárquicamente superiores (validez derivada). Pero, en segundo lugar, una norma puede pertenecer como norma independiente en un ordenamiento jurídico si aquella es reconocida directamente como tal por parte de los tribunales (validez originaria) ${ }^{41}$. Dicho de otro modo, como una norma directamente designada por el conjunto de reglas que los jueces utilizan para establecer cuáles son las normas que pertenecen al ordenamiento jurídico (regla de reconocimiento).

Una vez aclarado el marco conceptual en el que podemos decir que una norma puede pertenecer al ordenamiento jurídico, podemos presentar algunas maneras en las que un ordenamiento jurídico puede contener una norma sobre el precedente. Se trata, no obstante, únicamente de una enumeración no exhaustiva de formas en las que puede pertenecer la regla del stare decisis, siendo posible que haya otras formas de pertenencia. Quedará para otra ocasiones determinar si, y en qué sentido, los sistemas casacionales (y de recursos procesales, más en general) y de gobierno judicial, pueden generar - aunque sea indirectamente- sistemas de precedentes.

a) Por previsión normativa explícita. En primer lugar, un ordenamiento jurídico puede tener una regla del precedente cuando sus documentos autoritativos prevean una disposición normativa que explícitamente formula alguna regla del stare decisis. Cuáles de todas las posibles reglas del stare decisis sean las que están vigentes es cuestión contingente.

b) Por concretización de algún principio. En segundo lugar, es posible que, pese a que no se encuentre ninguna previsión normativa sobre la regla del stare decisis, aquella sea considerada como la concretización de algún principio jurídico (explícito

41 La lista de normas que pertenecen como normas independientes dentro de un ordenamiento jurídico es de lo más variado: desde la primera constitución, a las normas irregulares, pasando por las reglas que concretizan principios, las reglas (no positivizadas en muchos ordenamientos) para la resolución de antinomias, etc. Es decir, se trata de un conjunto de normas que nadie dudaría en calificar como pertenecientes al ordenamiento jurídico pero que no han sido emanadas por ninguna autoridad identificada por ninguna norma perteneciente al ordenamiento jurídico. 
o implícito). Es decir, la norma del stare decisis no ha sido expresamente formulada por el legislador pero se considera que aquella se deriva de algún principio jurídico ${ }^{42}$. Ahora bien, lo que determina la pertenencia a un ordenamiento de alguna regla del precedente como especificación de algún principio es que tal regla sea aceptada como una concretización válida de tales principios ${ }^{43}$, no la mera posibilidad de concretizarlo a partir de algún principio.

c) Por identificación de la regla del precedente como norma independiente (originaria). El consenso necesario para que una regla del stare decisis, producto de la concretización de algún principio jurídico, pertenezca a un ordenamiento sería un consenso, en cierto sentido, justificado jurídicamente, en la medida en que se trate de un consenso basado en la plausibilidad de derivar tal regla a partir de uno de algún principio. Sin embargo, tal consenso puede darse, por decirlo de algún modo, de manera más directa.

Es perfectamente posible que, pese al silencio del sistema de fuentes expresamente formulado en un ordenamiento (praeter legem), o incluso en contra de dicho sistema explícito de fuentes (contra legem), los jueces reconozcan como parte del ordenamiento una regla del stare decisis y estén dispuestos a aplicarla. Es decir, que los jueces consideren que hay una norma implícita en el ordenamiento que obliga a decidir los casos similares de manera similar, designando tal norma como una norma independiente (en el sentido de norma originaria del ordenamiento) ${ }^{44}$.

d) Por identificación de una o varias decisiones como precedente como normas independientes (originarias). Por último, es también posible que no haya una regla del precedente de carácter general, sino que se considere que un conjunto de decisiones expresan normas originarias. Es decir, aquí la norma válida en sentido originario no es la regla del stare decisis, sino la norma expresada por una o varias rationes decidendi.

\section{DESCUBRIENDO EL PRECEDENTE}

En esta sección me ocuparé de la identificación de la regla empleada por un órgano jurisdiccional para decidir una controversia, esto es, el descubrimiento de la ratio

${ }^{42}$ Los dos principios candidatos a expresar la regla del stare decisis son precisamente aquellos que justifican su existencia: el principio de seguridad jurídica y el principio de igualdad ante la ley. En relación al primero, no parece descabellado afirmar que una de las posibles concretizaciones del principio de seguridad jurídica es la regla según la cual que los casos similares deben juzgados de igual manera. Ello con el objetivo de que las expectativas de los ciudadanos sobre un tipo de decisiones jurisdiccionales se vean satisfechas. En relación al segundo, el principio de igualdad ante la ley parece justificar sobradamente que todos los casos de un cierto tipo deban ser decididos de la misma manera. Vid., Xiol, 2006; IgARTUA, 2006; MARINONI, 2012; Ruiz Miguel, 1997.

${ }^{43} \mathrm{Si}$ aceptamos que tales principios están presentes en la mayoría de los ordenamientos de nuestro entorno, esto podría llevarnos a concluir que en todos estos ordenamientos está presente la regla del stare decisis. Sin embargo, ello no es evidentemente así, al menos porque los diferentes ordenamientos parecen tener diferentes reglas del precedente.

${ }^{44}$ Este es, por ejemplo, el caso del Tribunal Constitucional colombiano; en cierto sentido, también del Tribunal constitucional español; y la base de la regla del autoprecedente por parte de la Cámara de los Lores británica. Sobre el Tribunal Constitucional colombiano, vid. BERnAL Pulido, 2008. Sobre el Tribunal Constitucional español, vid. Moral Soriano, 2002 y GASCón, 1993. Sobre la Cámara de los Lores, vid. Cross y HARRIS, 2011: 129. 
decidendi. No obstante, antes de pasar a analizar los problemas relativos a la identificación de la ratio decidendi es preciso volver a las formas en las que puede ser trazada la distinción entre obiter dicta y ratio decidendi.

Como ya sabemos (supra 2.2.2), la distinción entre obiter dicta y ratio decidendi se vuelve más relevante en la medida en que concibamos los precedentes como reglas y no como casos paradigmáticos. La razón es que si bien la distinción es conceptualmente relevante tanto si concebimos los precedentes como reglas como si los concebimos como casos paradigmáticos, en el segundo caso la distinción se hace extensionalmente mucho más difícil de trazar, cuando no imposible. Por esta razón, en este apartado me centraré exclusivamente en los problemas de identificación de la ratio decidendi cuando el precedente sea identificado como regla.

Cuando, por el contrario, configuramos el precedente como regla, la distinción entre obiter dicta y ratio decidendi se vuelve de lo más relevante. Esto no implica que alguna de las propiedades previstas en el antecedente de la regla aplicada por el juez sea perfectamente clara en el sentido de no vaga. Es, por supuesto, perfectamente posible concebir la decisión jurisdiccional como aplicación de una regla pero, sin embargo, que dicha regla sea intencionalmente vaga.

\subsection{Problemas de interpretación del precedente en sentido estricto}

El primer problema que aparece en relación con la identificación de la norma aplicada por un órgano jurisdiccional es la interpretación de las decisiones jurisdiccionales. Sin embargo, por «interpretación» podemos entender cosas muy diferentes. Por «interpretación en sentido estricto» entenderé la actividad de atribución de significado a textos (en este caso, al texto de la decisión jurisdiccional). Por «interpretación en sentido amplio», por el contrario, entenderé el conjunto de actividades que sirven para establecer la ratio decidendi pero que no consisten en la atribución de significado al texto con base en criterios interpretativos como, por ejemplo, la inducción o la identificación de qué hechos ha considerado como relevantes (de entre todos los hechos probados) el órgano jurisdiccional.

En relación con la interpretación en sentido estricto, en primer lugar, nos encontraremos con el problema de tener que identificar qué partes de la decisión constituyen la ratio decidendi y cuáles, sencillamente, son parte del obiter dicta. Surge, en este ámbito, también el problema del valor que debe atribuírsele a la propia declaración del órgano sobre cuál es el fundamento - en este contexto, la ratio decidendi- de su sentencia ${ }^{45}$.

En segundo lugar, en muchas ocasiones la ratio decidendi no está formulada en términos normativos sino que, por el contrario, aparece como una explicación de la decisión juridisdiccional. Dicho de otro modo, la norma que constituye la ratio decidendi no queda formulada en términos prescriptivos sino en términos descriptivos, lo que no ayuda precisamente a su identificación.

45 Como señala R. CROss, esto podría producir que el órgano afirmase que algunas cuestiones no congruentes o relevantes para el fallo tuvieran valor de precedente. $C f r$. CROss y HARRIs, 2011: 64 
En tercer lugar, del mismo modo que en muchas ocasiones los enunciados interpretativos que podemos emplear para atribuir significado a los enunciados normativos conducen a diferentes interpretaciones-producto (careciendo de meta-criterios últimos de origen jurídico que nos indiquen cuál de las interpretaciones es la correcta) (GUASTINI, 2014), igualmente la interpretación de los enunciados que aparecen en una decisión jurisdiccional pueden ser susceptibles de diferentes interpretaciones ${ }^{46}$. Ello se debe exactamente a la misma razón por la que podemos atribuir diferentes interpretaciones a los enunciados normativos: la pluralidad de criterios interpretativos, y la ausencia de meta-criterios últimos de corrección interpretativa de origen jurídico (LLEWELlYN, 1950).

Para entender el cuarto problema relativo a la interpretación en sentido estricto es necesario introducir una distinción ulterior de teoría general de la interpretación: aquella entre interpretación en abstracto e interpretación en concreto. Como es sabido, la interpretación en abstracto es la interpretación que es llevada a cabo más allá de cualquier caso individual, mientras que la interpretación en concreto es una interpretación dirigida al uso de la interpretación-producto para resolver un caso individual ${ }^{47}$.

Pues bien, cuando estamos frente a la interpretación en concreto de una decisión jurisdiccional, la atribución de significado a los enunciados de la decisión precedente está mediada por sesgos normativos. Es decir, la atribución de significado a los enunciados de la decisión que expresa el precedente va a estar determinada por la percepción del caso a resolver y por cómo este precedente puede afectar el caso a decidir. Dicho de otro modo: el intérprete va a ajustar la atribución de significado a la decisión objeto de interpretación con base en las consecuencias que tal interpretación produzca en el caso que ha de resolver.

Esto, es importante señalarlo, no implica que nunca sea posible establecer qué norma ha sido empleada para resolver un caso, ni que las decisiones judiciales sean siempre ambiguas, susceptibles de varias interpretaciones. El hecho de que sea o no posible determinar la ratio decidendi es una eventualidad que depende de que los diferentes criterios interpretativos conduzcan efectivamente a diferentes resultados interpretativos y de la propia redacción de la decisión. Sin embargo, parece que tales problemas se dan con bastante frecuencia.

\subsection{Problemas de interpretación en sentido amplio}

Si bien es cierto que buena parte de los problemas de la identificación de la ratio decidendi son problemas relativos a la interpretación en sentido estricto, es importante señalar que los problemas de distinción entre ratio y obiter no pueden ser reducidos

46 La decisión judicial, normalmente, interpreta textos normativos — disposiciones normativas de carácter autoritativo- pero puede interpretar también, a su vez, otras decisiones judiciales. Es decir, la interpretación de decisiones judiciales es en muchas ocasiones una meta-interpretación, esto es, interpretación de cómo se han interpretado otros textos.

47 GUASTINI en realidad emplea la expresión «interpretación en concreto» para referirse a dos actividad diferentes: en primer lugar, a la subsunción; en segundo lugar, a la actividad de (re-)interpretación en sentido estricto que consiste en ajustar el significado de los enunciados precisamente con el objetivo de esclarecer si aquellos expresan una proposición bajo la cual subsumir un caso individual. 
únicamente a problemas de interpretación. Es decir, es posible que no tengamos dudas acerca del significado de las palabras empleadas en la decisión jurisdiccional pero que, sin embargo, con base en dicho material no sea posible todavía identificar la regla aplicada.

En este sentido se pueden identificar no menos de cinco problemas de interpretación en sentido amplio que no son dependientes de la interpretación en sentido estricto.

En primer lugar, si presuponemos que la justificación de la regla del stare decisis se encuentra en los principios de igualdad y seguridad jurídica ${ }^{48}$, entonces aquello relevante es determinar qué norma ha sido la que ha utilizado el órgano jurisdiccional para decidir la controversia, no la norma que ha presentado como justificación de su decisión. Es decir, aquello relevante es la premisa normativa que ha utilizado el juez en su fuero interno ${ }^{49}$ : la norma que funcionó como premisa mayor en su razonamiento, y no necesariamente aquella que mencionó.

Pues bien, desde este punto de vista, no hay razón alguna para presuponer que la decisión mencione todas y cada una de las propiedades que han sido consideradas como relevantes a la hora de decidir. Dicho de otro modo, no hay ninguna razón para pensar que los jueces han hecho explícitas o mencionado todas las propiedades relevantes contempladas en el antecedente de la norma que ha aplicado. De hecho, a decir verdad, no hay razón alguna para pensar que los jueces mencionen las razones por las que deciden realmente las controversias (POSNER, 2011).

En segundo lugar, no es infrecuente que los órganos jurisdiccionales, especialmente los administrativos, mencionen únicamente disposiciones normativas sin especificar cómo las están interpretando. Es decir, sin hacer explícita cuál es la norma que están aplicando ${ }^{50}$ sino únicamente la disposición de la que la derivan. Este problema, que no es de interpretación en sentido estricto sino de meta-interpretación, se agrava especialmente cuando lo que están aplicando los jueces no son normas provenientes de enunciados normativos, sino precedentes que tienen como origen otras decisiones jurisdiccionales.

En tercer lugar, es posible que el órgano haya considerado diferentes disposiciones y/o diferentes normas como contribuyentes para su decisión judicial. Sin embargo, configurando de este modo la decisión, el problema es que no sería posible identificar cuáles son los factores necesarios y suficientes, es decir, las propiedades relevantes de la regla que ha aplicado.

48 Algunos autores, como Marina GASCÓN, justifican la regla del precedente en la interdicción de la arbitrariedad judicial. En este sentido, aquella funcionaría como un límite formal a la argumentación judicial; en particular, aquella equivaldría al principio kantiano de universalidad. Sin embargo, GASCÓN insiste en que dicha justificación no estaría basada en el principio de igualdad. GASCÓN, 1993: 59. Vid. también J. WALDRON, 2012: 1-31.

49 Siempre que se conciba el precedente de forma psicológica. $C f r$. CHIASSONI, 2012: 219. Esta parece ser la tesis de CROSs: «[E]ntre todas las proposiciones dictadas por el juez, únicamente se consideran parte de la ratio decidendi aquellas proposiciones que parezcan haber sido consideradas por él como necesarias para su decisión»; «Obsérvese que el descubrimiento de la ratio decidendi del caso anterior es principalmente un problema de tipo psicológico» (cursiva mía). Cfr. R. CROSs y HARRIs, 2012: 63, 226.

50 «Sin esa enunciación, el fundamento puede ser prácticamente cualquier cosa». Cfr. SCHAUER, 2013: 70. 
En cuarto lugar, es posible que una decisión jurisdiccional contenga votos concurrentes, es decir, votos particulares que apoyan la decisión pero que la fundamentan de manera diferente. No solo es discutible cuál sea el papel de dichos votos en la identificación de la ratio decidendi, sino que también es dudoso qué papel están llamados a jugar los votos disidentes.

Por último, en los casos de ponderaciones entre principios jurídicos es perfectamente posible que se indiquen cuáles han sido los principios y razones tenidos en cuenta, pero no se especifique qué regla es la que se obtiene de tal ponderación y, en consecuencia, qué regla se está aplicando. Puede darse el caso de que no se mencione cuál es el resultado de la ponderación, señalándose únicamente cómo resuelve dicha ponderación el caso. Y algo parecido se podría decir respecto a la concretización de principios, es decir, la derivación de una regla a partir de un principio jurídico.

\subsection{El problema la inducción}

Cuando, después de la interpretación en sentido estricto de los enunciados que expresan la decisión jurisdiccional, no se ha conseguido determinar la ratio decidendi de la decisión, se pueden tomar dos caminos diferentes para intentar identificar la regla aplicada. El primero de ellos es la reinterpretación (en sentido estricto) del texto de la sentencia, intentando hacerle decir más de aquello que, a la luz de los criterios interpretativos disponibles, dice la decisión. El segundo camino consiste en tratar de reconstruir la regla aplicada a través del fallo de la decisión y los hechos probados, mediante un argumento por generalización ${ }^{51}$.

A continuación analizaré dos problemas que enfrenta este segundo tipo de operaciones en las que se trata de identificar la ratio decidendi a la luz del dispositivo de la sentencia y de los hechos probados. Dejo de lado el primer tipo de actividad de sobreinterpretación porque parece tratarse de un caso de discrecionalidad en sentido fortísimo.

Pues bien, en primer lugar, es frecuente considerar que, a la luz de los hechos probados y de la norma individual decretada por el juez, es posible establecer qué regla ha aplicado. Sin embargo, para que dicha operación fuera plausible, sería necesario establecer cuáles, de entre todos los hechos considerados como probados, han sido considerados como relevantes por el tribunal ${ }^{52}$. Ahora bien, si fuéramos capaces de identificar cuáles son los hechos relevantes del caso, entonces ya habríamos descubierto las propiedades que forman el antecedente de la regla aplicada por el tribunal (teniendo la solución normativa en el fallo) ${ }^{53}$. Se trata, por tanto, de una falacia de argumento circular.

51 Por supuesto, si bien es posible distinguir conceptualmente estas dos operaciones, en la práctica son llevadas a cabo de manera conjunta.

52 Esta es la crítica que tradicionalmente se ha venido desarrollando en contra del método desarrollado por GoOdHart para la identificación de la ratio decidendi. Vid. GoOdHart, 1930; MonTrose, 1956; STONE, 1959.

53 Autores como GOODHART han sostenido que cuáles sean las propiedades que hay que considerar como relevantes para la determinación de la ratio decidendi vendría dado por el resto de normas del ordenamiento. 
En segundo lugar, incluso aunque fuéramos capaces de establecer cuáles son los hechos que han sido considerados relevantes, con base en dichos hechos y el dispositivo de la sentencia sería posible identificar — no una, sino- infinitas normas que igualmente justificarían la misma decisión ${ }^{54}$. Se trata sencillamente del más que conocido problema -indicado prontamente por los realistas estadounidenses en este ámbito55 - de la inducción: la imposibilidad de concluir válidamente desde el punto de vista lógico qué regla se está utilizando a partir de la constatación de ejemplos de uso de la regla ${ }^{56}$.

Por último, es importante señalar que algunos autores han considerado que, más allá del valor que se otorgue a la reiteración de un precedente (esto es, que no se trate de una única decisión precedente sino que haya varias o una cadena de precedentes), tal reiteración serviría para identificar con mayor claridad cuál es el precedente. Sin embargo, es preciso descartar tal idea. Si el problema, como parece, es la determinación de la norma aplicada por el tribunal, entonces surgen dos problemas en relación con lo que aportaría la reiteración del precedente.

El primero de ellos es que nada impide que el segundo precedente haya interpretado mal el primero y, en tal caso, en lugar de uno tengamos dos precedentes parcialmente solapados. Eliminando de la ecuación las atribuciones de sentido claramente absurdas (aquellas que no respetan sincrónicamente los criterios vigentes de interpretación), si fuéramos capaces de identificar una interpretación errónea del precedente, sería porque ya habríamos identificado cuál es la ratio decidendi del caso.

En segundo lugar, el hecho de que tengamos una decisión ulterior, incluso aunque sea idéntica, no tiene por qué facilitar la identificación del precedente vía inducción, precisamente porque la presentación de nuevos casos de aplicación de la regla no permite establecer concluyentemente qué norma ha sido aplicada. En caso contrario, sencillamente presupondríamos haber resuelto el problema de la inducción (y/o del wittgensteniano seguimiento de reglas), lo que estamos lejos de conseguir.

\footnotetext{
Surge inmediatamente una cuestión: ¿qué propiedades, de todas las que contempla el derecho, son las que deben ser tenidas en cuenta? o, dicho de otro modo, ¿qué criterio de relevancia debemos emplear para identificar las normas relevantes a estos fines? Esta parece ser también la posición de SCHAUER. Cfr. SCHAUER, 2013: 65. Sin embargo, SCHAUER había sostenido con anterioridad una tesis acerca de la convencionalidad de los criterios de relevancia; dicho de otro modo, que existiría una convención, desde luego profunda, acerca de cuáles son los criterios de relevancia. Sin embargo, dicha tesis puede ser refutada haciendo referencia, rawlsianamente, al hecho del pluralismo de las concepciones del bien.

${ }_{54}$ Este punto puede comprenderse fácilmente mediante un ejemplo: si una decisión judicial ha considerado que el sujeto $\mathrm{S} 1$ asesinó al sujeto S2, y el dispositivo de la sentencia dice que S1 debe permanecer 15 años en una cárcel, alguien podría concluir que la regla aplicada sería algo parecido a N1: Quien asesine tendrá pena de 15 años de cárcel. Sin embargo, dicha norma individual también estaría justificada por la norma N2 (Quien asesine a otro mediando una relación de enemistad entre víctima y delincuente, entonces 15 años de cárcel), la norma N3 (Quien asesine a otro salvo que haya una relación afectiva entre las partes, entonces 15 años de cárcel), la norma N4 (Quien asesine habiendo una relación laboral entre las partes, entonces 15 años de cárcel), etcétera.

${ }_{55}$ La formulación más célebre de este problema se encuentra en OLIPHANT, 1928. Sin embargo, también es identificada por el propio LLEWELLYN (LLEWELlyn, 2008: 61-66), por Felix COHEN (COHEN, 1960, 88) y por Max RADIN (RADIN, 1946: 140).

${ }_{56}$ Aquí no estoy sosteniendo, ni tomando posición de ningún modo, respecto a la tesis de Kripke-Wittgenstein acerca de la existencia de reglas. Aquí únicamente estoy presuponiendo (que no aceptando) la existencia de normas (o reglas) pero poniendo en cuestión la posibilidad de identificarlas en este ámbito.
} 
Cuando se presentan casos de indeterminación acerca de la ratio decidendi y, aún así, se identifica una específica norma como la aplicada, dicha actividad, antes que puramente cognitiva, parece más bien una reconstrucción valorativa o axiológica. Es decir, lo que se hace en estos casos es llevar a cabo una operación de carácter valorativo (en abstracto y/o en concreto) para identificar cuáles son las propiedades que el órgano jurisdiccional debería haber tenido en cuenta: un juicio de carácter práctico acerca de cuáles son las propiedades que «razonablemente» debería haber tenido en cuenta el órgano a la hora de decidir el caso. Por supuesto, nada garantiza que los criterios empleados sean los mismos.

\section{QUÉ HACER CON UN PRECEDENTE}

Una vez que hemos identificado el tipo de regla del stare decisis presente en el ordenamiento jurídico de referencia y la ratio decidendi de la decisión jurisdiccional, llegamos a la fase de la aplicación del precedente. Obviamente, es perfectamente posible que se identifique la ratio decidendi de una decisión que cuenta como precedente y que, sin embargo, se considere simplemente como no aplicable porque el caso a decidir no satisface las propiedades de aplicabilidad interna del precedente. Pero, pese a que se haya identificado el precedente, y que el caso satisfaga las condiciones internas de aplicación de aquel, la aplicación del precedente es solo una de las posibilidades que el órgano jurisdiccional tiene a su disposición.

Aunque limitemos el discurso sobre la aplicación del precedente únicamente a los precedentes entendidos como reglas, ello no implica que su aplicación sea una tarea meramente mecánica. Ello porque no existe ningún sistema jurídico - aunque sería perfectamente posible - en el que los precedentes sean absolutamente vinculantes (CHIASSONI, 2012: 245). Dicho de otro modo: no existe ningún ordenamiento jurídico en el que el órgano jurisdiccional tenga la obligación no excusable de aplicar un precedente (entendiendo por «aplicar el precedente» utilizar la misma norma que fue usada como premisa mayor de la decisión jurisdiccional precedente (vid. supra 2.4.1.2). Salvo en el caso en que existiera en un ordenamiento el más alto grado de vinculatoriedad (entendida como obligación institucional no excusable bajo ninguna condición de aplicar el precedente), los órganos jurisdiccionales siempre tienen la posibilidad (en sentido normativo) de no aplicar el precedente.

\subsection{No aplicar el precedente}

La primera posibilidad que voy a explorar es la no aplicación del precedente. A continuación, presentaré seis de las operaciones más típicas mediante las que se puede rechazar la aplicación de un precedente: no aplicar, derrotar, distinguir, modificar, abrogar y anular un precedente ${ }^{57}$. Aquí no voy a emplear la terminología propia de la

57 Se trata, dicho sea de paso, solo de las más frecuentes, siendo posible identificar otras. Por ejemplo, Jeffrey MARSHALL identificó, irónicamente, hasta 33 operaciones que se podían hacer con un precedente. $C f r$. MARSHALL, 1993. 
tradición del common law que es aquella más frecuentemente empleada para analizar las formas en las que es posible no aplicar el precedente debido a la ambigüedad de las dos expresiones más comúnmente usadas: distinguish y overruling.

Estas seis formas de rechazar la aplicación de un precedente constituyen una escala de menor a mayor grado de rechazo del precedente. Veamos cada una de ellas separadamente.

\subsubsection{No aplicar}

Lo primero que podemos hacer para no aplicar un precedente es, sencillamente, considerar que el caso a decidir no satisface las condiciones de aplicabilidad interna de la ratio decidendi del precedente. Dicho de otro modo, la norma expresada en el precedente no es aplicable al caso porque aquella regula un supuesto de hecho diferente, o porque, aunque regule el mismo caso, el supuesto precedente sería, en la parte coincidente, únicamente obiter dictum. Este caso constituye el grado mínimo de rechazo del precedente pues mediante esta operación lo único que se hace es afirmar que el caso a decidir no cumple las propiedades tenidas en cuenta en el antecedente de la norma que constituye la ratio decidendi.

\subsubsection{Derrotar}

Aquí no entraré en un análisis pormenorizado acerca de qué significa derrotar una norma, y me limitaré a emplear dicha noción en el ámbito de los precedentes ${ }^{58}$. Pues bien, derrotar un precedente implica considerar, en primer lugar, que aquel es internamente aplicable, es decir, que el caso a decidir satisface las propiedades previstas en el antecedente de la norma. Es más, se considera que el precedente resuelve el caso a decidir (razón prima facie) pero, sin embargo, debido a la presencia de otras razones más poderosas en el caso, aquel es dejado de lado o no aplicado. Es decir, se derrota un precedente cuando, a la luz de todas las consideraciones relevantes del caso (all things considered), se considera que hay razones más importantes o de mayor peso para decidir el caso mediante otra u otras normas. Se trata obviamente de una cuestión valorativa que depende de las preferencias de los intérpretes.

\subsubsection{Distinguir}

En la siguiente operación típicamente desarrollada por los tribunales para evitar la aplicación de un precedente, la distinción, nuevamente se considera que el caso a decidir satisface las condiciones de aplicabilidad interna del precedente. Es decir, el precedente es, al menos prima facie, aplicable.

Sin embargo, al utilizar este mecanismo lo que se está haciendo es considerar que su aplicación al caso concreto no resultaría conveniente desde el punto de vista axioló2003.

58 Para el análisis de la cuestión de la derrotabilidad de las normas jurídicas, vid. RODRÍGUEZ y BAYÓN, 
gico: su aplicación resultaría injusta. Ello porque se considera que en el caso a decidir concurre alguna propiedad relevante que, de ser tomada en cuenta, haría que razonablemente el caso fuera resuelto de otra manera (por supuesto, más justa).

Como es bien sabido, la distinción de normas es una actividad del todo análoga a la construcción de lagunas axiológicas mediante el argumento de la disociación. A saber: aquel mecanismo por el que el intérprete considera que un caso queda regulado por una norma pero que, de haberse tenido en cuenta una propiedad del caso individual que se debe decidir, la calificación jurídica del hecho habría sido diferente ${ }^{59}$.

Esto no hace que el precedente P1 pierda validez o fuerza justificativa. Por el contrario, lo que se hace mediante la distinción es señalar una excepción al precedente P1, generando un nuevo precedente P2 (si el órgano tiene la competencia para hacerlo), más especial ${ }^{60}$ respecto al precedente $\mathrm{P} 1$, que resuelve la cuestión de manera diferente (DUXBURY, 2008: 115).

\subsubsection{Modificar}

Cosa diferente a distinguir un precedente es modificarlo, considerando que aquello que normalmente había sido considerado como la ratio decidendi del precedente es en realidad otra. Esto suele realizarse llevando a cabo una modificación de las partes consideradas ratio decidendi y obiter dicta respectivamente, es decir, sosteniendo que la ratio decidendi del caso precedente, en contra de lo que pudiera parecer, en realidad es otra.

La diferencia respecto a la distinción del precedente es que aquí no se genera un nuevo precedente P2 más fino - una norma con un antecedente en el que hay más propiedades - respecto al precedente original $\mathrm{P} 1$, sino que directamente se modifica el precedente $\mathrm{P} 1$, sustituyendo alguna de las propiedades que originariamente estaban en su antecedente por otra nueva. Cuando estamos frente a la modificación de un precedente, tal operación suele ser justificada como una aclaración respecto del precedente anterior.

\subsubsection{Abrogar}

Estamos frente a la abrogación de un precedente toda vez que un órgano jurisdiccional considera que un precedente $\mathrm{P} 1$, si bien no es contrario a derecho, no debe seguir siendo parte del ordenamiento jurídico. Es decir, aquí lo que tenemos es un acto de derogación por razones de oportunidad, porque - aunque la decisión

59 Caben dos formas argumentativas para distinguir un precedente: el primero de ellos es mediante un argumento contrafáctico según el cual, si tal propiedad se hubiera presentado en el caso anterior, habría sido tenida en cuenta por el órgano jurisdiccional; el segundo, por el contrario, no apela a la actuación del órgano jurisdiccional sino que afirma que es razonable introducir tal distinción.

60 Por «más especial» aquí estoy considerando sencillamente la presencia, comparativamente, de alguna propiedad suplementaria en el antecedente de la norma. Para una discusión sobre la relación de especialidad entre normas, vid. S. ZORZETTO, 2010. 
precedente no se ha convertido en una decisión contraria a derecho- ya no se considera la mejor solución jurídicamente posible. Ello normalmente se justificará en un cambio de las circunstancias fácticas, sobre todo en precedentes de vieja data, arguyendo que su aplicación al momento actual conduciría a consecuencias no deseables.

Si bien en el caso de la anulación no es imprescindible que el tribunal genere un nuevo precedente - ya que es posible que el tribunal se limite a derogar una decisión pasada ${ }^{61}$ - ello no significa que la abrogación no requiera de justificación. Antes bien, el órgano jurisdiccional que abroga un precedente debe justificar tal operación, argumentando que si bien el precedente no es contrario a derecho, un cambio en las circunstancias empíricas hace que su aplicación no conduzca a las mejores consecuencias jurídicas posibles ${ }^{62}$.

\subsubsection{Anular}

Estamos frente a la anulación de un precedente toda vez que un tribunal elimina, anulándolo, un precedente judicial. Ahora bien, la anulación de precedentes tiene un efecto diferente a la mera abrogación. Cuando tenemos la abrogación de un precedente, lo que se sigue es únicamente que la norma deja de formar parte de una clase, esto es, deja de formar parte del derecho; dicho en otros términos, el precedente ya no está investido de autoridad. Cuando, por el contrario, tenemos una anulación, los efectos parecen más severos.

Para que el órgano jurisdiccional pueda anular el precedente debe fundar su decisión en su no juridicidad, es decir, aquel debe ser contrario a Derecho, y en tal consideración debe justificarse su anulación ${ }^{63}$. En este sentido, es posible afirmar que la anulación no implica únicamente la derogación del precedente sino su consideración negativa ${ }^{64}$ : lo que sucede no es solo que ya no forma parte del derecho sino que su uso está prohibido ${ }^{65}$.

${ }^{61}$ En efecto, en ocasiones los tribunales consideran que un precedente no es idóneo pero se abstienen de sustituir la ratio decidendi del caso derogado con otra. Esto es lo que R. CROSS y J. W. HARRIS llaman debilitamiento (undermining) del precedente. No obstante, deseo subrayar que la noción de abrogación que aquí estoy proponiendo no depende de la sustitución de un precedente con otro, sino de si el tribunal se limita a considerar que un precedente ya no forma parte del derecho o si, por el contrario, además considera negativamente tal precedente, calificando su uso como prohibido. En este último caso estaríamos frente a un acto de anulación. Vid. R. CROSS y HARRIS, 2012: 158.

62 Esto es lo que Bernal llama «error de idoneidad». Cfr. C. Bernal Pulido, 2008: 92.

${ }_{63}$ Según SCHAUER, para que sea derogable el precedente debe tener especiales consecuencias negativas, o bien debe ser de una gran magnitud. Es inútil decir que ambas consideraciones son de carácter valorativo o axiológico. Cfr. SCHAUER, 2013: 75.

${ }^{64}$ Para entender este punto, tal vez sea conveniente trazar una analogía —algo imprecisa, a decir verdad - con el caso en que un juez utiliza una norma abrogada por el legislador para resolver una controversia o, en cambio, usa una norma expulsada por el órgano competente por ser inconstitucional. Respecto del primer caso, probablemente diríamos que está mal fundada la decisión. Respecto del segundo, diríamos que la decisión es antijurídica. Parece que en este caso el reproche es mayor.

${ }_{65}$ Por supuesto, la posibilidad de llevar a cabo estas operaciones depende del sistema de precedentes que rija en el concreto ordenamiento jurídico. En concreto, de las normas de competencia entre los tribunales. 


\subsection{Aplicación del precedente}

Una vez que ya se ha identificado la ratio decidendi del precedente a aplicar, y se ha concluido que aquel es aplicable all things considered al caso que se ha de decidir, pueden surgir todavía otros dos problemas. El primero es que el precedente, pese a ser internamente aplicable, sea un precedente vago. El segundo de ellos se refiere a la multiplicidad de precedentes y a las antinomias que pueden surgir entre aquellos.

\subsubsection{Vaguedad del precedente}

El primer problema que debemos afrontar a la hora de aplicar el precedente es su vaguedad. Por vaguedad del precedente estoy entendiendo el hecho de que una o varias de las propiedades del antecedente de la ratio decidendi sea vaga, esto es, que aquella haga referencia a una propiedad cuya aplicación puede generar dudas extensionalmente, identificándose casos claros de aplicación y no aplicación, y otro grupo de casos no claros de aplicación.

Pues bien, nada garantiza que, pese a que hayamos identificado en abstracto la ratio decidendi de un precedente en cuanto regla, y que tal norma parezca internamente aplicable en el precedente que la formula, aquella sea vaga para el nuevo caso al que aplicar el precedente. Del mismo modo que si se tratara de una regla proveniente de un órgano legislativo, en estos casos la única forma de resolver este margen de indeterminación parece ser reinterpretando el enunciado que expresa la norma. Es decir, atribuir a la decisión jurisdiccional un nuevo sentido más preciso (reinterpretación en concreto) que haga que al texto decir que, en realidad, la norma aplicada es una norma no vaga.

\subsubsection{Multiplicidad de precedentes}

El segundo problema que se encuentra en la aplicación del precedente es la multiplicidad de aquellos. Como bien se encargaron de reflejar varios realistas estadounidenses (Hermann OliPHANt y Jerome Frank, entre otros) (OlIPHANT, 1928; FranK, 1970: 163 y ss.) el problema no se encuentra únicamente en la determinación de qué norma ha aplicado un tribunal sino que, además, en muchas ocasiones sucede que diferentes tribunales, o incluso el mismo tribunal, han decidido casos parecidos de maneras diferentes incompatibles con base en el mismo precedente ${ }^{66}$.

Es posible imaginar dos formas sobre cómo resolver las antinomias entre diferentes precedentes.

5.2.2.1. El primer método para resolver sus posibles antinomias sería realizando un juicio de mayor relevancia, esto es, estableciendo a cuál de los dos precedentes aplicables se parece en mayor medida el caso a decidir. Desde este primer punto de vista,

${ }^{66}$ Es importante señalar que, para identificar una antinomia entre precedentes, previamente debe haberse identificado las respectivas ratio decidendi. Por tanto, y del mismo modo que cuando nos encontramos con una antinomia entre normas de origen legislativo, es preciso llevar a cabo la interpretación de las decisiones jurisdiccionales que expresan dichas normas. 
en ausencia de otras razones que determinen el sentido de la decisión, se consideran las razones subyacentes de cada precedente, y se determina cuál de ellos tiene mayor peso. Tal forma de resolver la antinomia entre precedentes convierte a ambos en casos paradigmáticos y tiene el inconveniente de que, salvo que suscribamos alguna suerte de objetivismo moral, la decisión acerca de cuál de los dos precedentes debe prevalecer parece ser dejado a las preferencias prácticas del órgano jurisdiccional.

5.2.2.2. La segunda forma en la que se podrían intentar resolver las antinomias entre precedentes es aplicando los criterios para la resolución de antinomias entre normas en general. Sin embargo, a este respecto es necesario realizar cuatro acotaciones.

La primera de ellas es que su aplicabilidad es puramente contingente, esto es, aquella dependerá de si hay una norma en el respectivo ordenamiento que lo permita.

En segundo lugar, si bien los métodos para la resolución de antinomias suelen ser presentados como aproblemáticos, lo cierto es que aquellos chocan y no siempre está claro cuál es el que debe prevalecer como, por ejemplo, en el caso de los choques entre temporalidad y especialidad (MORESO y VILAJOSANA, 2004: 106 y ss.).

En tercer lugar, no está claro que, al menos, el criterio jerárquico sea directamente aplicable a la resolución de antinomias entre precedentes. Ello por dos razones: por un lado, porque hay precedentes que vinculan las decisiones de órganos jurisdiccionales superiores respecto de inferiores ${ }^{67}$; por el otro, porque hay casos en los que resulta imposible establecer cuál de dos tribunales es el superior puesto que no pertenecen a la misma estructura institucional ${ }^{68}$.

La última acotación importante sobre la aplicación de los criterios para la resolución de antinomias en relación con los choques entre precedentes, es que tales criterios no contemplan dos elementos que suelen ser considerados fundamentales a la hora de resolver los conflictos entre precedentes: por un lado, la reiteración o número de veces en las que el precedente ha sido empleado y, por el otro, la antigüedad del mismo. Sin embargo, además de ser bastante vagos, no está claro cómo interactuarían estos con el resto de criterios.

\section{ALGUNAS CONCLUSIONES PROVISIONALES}

Además de por aquellos motivos estructurales que se han mencionado, existen buenas razones para tener una regla del precedente. La regla del stare decisis parecería

67 Me refiero al así llamado precedente vertical ascendente. Un ejemplo de aquel sería la consulta vinculante de la Agencia tributaria española hacia los Tribunales económico-administrativos. Sobre la noción de precedente vertical ascendente, vid. CHIASSONI, 2004: 100.

${ }_{68} \mathrm{Me}$ refiero al caso del precedente internacional y al precedente oblicuo. Por precedente internacional no me refiero solo a los precedentes que surgen de decisiones de tribunales internacionales sino también de precedentes de tribunales extranjeros. En este sentido, basta con pensar en la relevancia que tienen algunos órganos jurisdiccionales de manera transnacional, como la Corte Suprema estadounidense o el Tribunal Constitucional alemán. Con «precedente oblicuo» me refiero a aquellos casos en los que las decisiones de un órgano jurisdiccional tienen valor de precedente sobre las decisiones de otros órganos jurisdiccionales nacionales pero que no forman parte de un mismo cuadro orgánico. Por ejemplo, el papel que cumplen las decisiones del Consejo de Estado español hacia los tribunales de justicia. 
ser reflejo de algunos de los más importantes ideales que vinculamos con el derecho. Entre ellos, por mencionar solo los más importantes, estarían la igualdad, la seguridad jurídica, la eficiencia, la limitación de la discrecionalidad judicial y el estado de derecho.

Mejor dicho: antes que el reflejo de tales ideales, de manera no metáforica sería más conveniente decir que se trata de un instrumento, un medio, a través del cual tratamos de satisfacer tales valores, ideales o principios. En este sentido, un análisis racional de las virtudes y defectos de la regla del precedente no puede no ser un análisis de carácter técnico, es decir, un análisis basado en la capacidad real de tal instrumento para dar satisfacción a dichos ideales. Este creo que es el único sentido en el que es posible preguntarse sobre la conveniencia de adoptar tal regla.

Mis conclusiones no son, en este sentido, de rechazo a la regla del stare decisis. Se ha mostrado con claridad que seguir el precedente es cualquier cosa menos una actividad mecánica. Por el contrario, implica múltiples decisiones basadas en última instancia en consideraciones de carácter no técnico o no descriptivo. En este sentido, es importante señalar que si lo que se pretende es reducir la discrecionalidad judicial al mínimo, la regla del precedente no es precisamente un óptimo como mecanismo. Antes bien, en lugar de eliminar la discrecionalidad judicial, lo que hace es transformarla, convirtiendo tal discrecionalidad en un amplio margen de apreciación acerca de la propia regla del stare decisis y de la conveniencia o no de seguir la misma ratio decidendi.

No se trata únicamente de que vuelva a entrar por la ventana aquello (la discrecionalidad) que había salido por la puerta. Si bien la regla del stare decisis reduce globalmente la discrecionalidad judicial, lo cierto es que, además, la transforma. En un ordenamiento sin tal regla, el ejercicio de discrecionalidad pasará probablemente por la interpretación de los enunciados normativos y por la invocación de principios. En un sistema con regla del precedente, por el contrario, aunque globalmente disminuya, la discrecionalidad tiende a ejercerse en más sedes y de diferente manera: en la interpretación de las sentencias, en la inducción de la ratio decidendi, en la comparación de casos paradigmáticos, etcétera.

Tal vez sería bueno preguntarse si deseamos que la discrecionalidad sea ejercida en cada uno de los ámbitos de nueva discrecionalidad que abre la regla del stare decisis o si, por el contrario, no será mejor que la discrecionalidad judicial esté circunscrita a la apreciación directa del caso. Dicho de otro modo: si, en lugar de dar el espacio para que los jueces ejerzan discrecionalidad en cuestiones aparentemente técnicas (la determinación de la ratio decidendi o su aplicabilidad), no sería mejor que tal discrecionalidad fuera ejercida directamente en relación con la justicia del caso concreto. Pero esa es una cuestión que no es posible abordar aquí.

\section{BIBLIOGRAFÍA}

ACCATINO, D., 2002: «El precedente judicial en la cultura jurídica chilena», en Anuario de la Sociedad Chilena de Filosofía Jurídica y Social.

Bernal Pulido, C., 2008: «El precedente judicial en Colombia», en Revista Derecho del Estado, 21. 
Bravo-Hurtado, P., 2013: «Hacia los precedentes en Chile: Reforma Procesal Civil y Fuentes del Derecho», en Revista Chilena de Derecho, 40, 2.

CARACCIOlO, R., 1988: Sistema jurídico. Problemas actuales, Madrid: Editorial del BOE.

Chiassoni, P., 2004: «Il precedente giudiziale: tre esercizi di disincanto», en Analisi e Diritto.

— 2012: «¿Son vinculantes los precedentes judiciales civiles?», en Desencantos para abogados realistas, Bogotá: U. del Externado de Colombia.

Conen, F., 1960: «The Problems of a Functional Jusrisprudence», en The Legal Conscience, New Haven: Yale University Press.

Cross, R., y Harris, J., 2012: El precedente en el Derecho inglés, Madrid: Marcial Pons.

DìEZ SASTRE, S., 2008: El precedente administrativo, Madrid: Marcial Pons.

Duxbury, N., 2008: The Nature and Authority of Precedent, Cambridge University Press.

Frank, J., 1953: «Some Tame Reflections on Some Wild Facts», en S. RatnER. (ed.), Vision and Action. Essays in Honor of Horace M. Kallen on his 70th Birthday, New Brunswick: Rutgers University Press.

- 1970: Law and the Modern Mind, Gloucester: Peter Smith.

GASCÓN, M., 1993: La técnica del precedente y la argumentación racional, Madrid: Tecnos.

GoODHART, A., 1930: «Determining the Ratio Decidendi of a Case», en The Yale Law Journal, 40, 2.

GUASTINI, R., 2014: Interpretar y argumentar, Madrid: CEPC.

IgARTUA, J., 2006: «La fuerza vinculante del precedente judicial», en Isegoría, 35.

ITURRALDE, V., 2014: «Precedente judicial», en Eunomia, 6, disponible online en http://eunomia.tirant.com/? $p=1523$ (13 de junio de 2014).

LAPORTA, F., 1997: «Vindicación del precedente judicial en España», en Anuario de la Facultad de Derecho de la Universidad Autónoma de Madrid, 1.

- 2009: «La fuerza vinculante del precedente y la lógica del precedente», en V. FERRERES y J. XIoL, La vinculatoriedad del precedente, Madrid: Fundación Coloquio Jurídico Europeo de Madrid.

LARSEN, A., 2013: «Factual Precedents», Faculty Publications, 1667, disponible online en $b t t p: / /$ scholarship.law.wm.edu/facpubs/1667 (13 de junio de 2014).

LegarRe, S., y Rivera, J., 2006: «Naturaleza y dimensiones del "stare decisis"», en Revista Chilena de Derecho, 33, 1.

LLEWELYN, K., 1950: «Remarks on the Theory of Appellate Decision and the Rules or Canons About How Statutes are to Be Construed», en Vanderbilt Law Review, 395, 3.

- 2008: The Bramble Bush, Oxford University Press.

LuPO, N. (ed.), 2014: «Il precedente parlamentare tra Diritto e politica», Il Mulino.

MacCormick, N., y Summers, R. S. (eds.), 1997: Interpreting precedents. A Comparative Study, Ashgate: Aldershot.

MARINONI, L., 2012: «El precedente en la dimensión de la seguridad jurídica», en Ius et Praxis, 1.

MARSHALl, J., 1993: «Trentatre cose che si possono fare con i precedenti», en Ragion Pratica, 6.

Montrose, J., 1956: «Reasoning, Ratio Decidendi and Denning L. J.», en Modern Law Review, 19,5 .

Moral Soriano, L., 2002: El precedente judicial, Madrid: Marcial Pons.

Moreso, J., y Vilajosana, J., 2004: Introducción a la teoría del derecho, Madrid, Marcial Pons.

NúÑEZ VAquero, A., 2013: «Ciencia jurídica realista: modelos y justificación», en Doxa, 35.

OliPhant, H., 1928: «A return to stare decisis», en American Bar Association Journal, 14, 71. 
Orozco MuÑoz, M., 2011: La creación judicial del derecho y el precedente vinculante, Madrid, Aranzadi.

Posner, R., 2011: Cómo deciden los jueces, Madrid: Marcial Pons.

Prieto SAnCHís, L., 1991: «Notas sobre la interpretación constitucional», en Revista del Centro de Estudios Constitucionales, 9.

RADIN, M., 1946: «The Trial of the Calf», en Cornell Law Quaterly, 137.

RAZ, J., 1985: La autoridad del derecho, México, UNAM.

RODRígueZ, J., y BAYÓN, J., 2003: Relevancia normativa en la justificación de las decisiones judiciales: el debate Bayón-Rodríguez sobre la derrotabilidad de las normas jurídicas, Bogotá: U. del Esternado.

Ruiz Miguel, A., 1997: «Equality before the Law and Precedent», en Ratio Juris, 10, 4.

SCHAUER, F., 1986-1987: «Precedent», en Stanford Law Review, 39.

- 2007: «Why Precedent in Law (and Elsewhere) is not Totally (or Even Substantially) About Analogy», en Harvard University, Faculty Research Working Papers Series.

- 2013: Pensar como un abogado, Madrid: Marcial Pons.

SHINNER, R., 2014: «Ratio Decidendi», en IVR Encyclopedie, disponible online: http://ivr-enc. info/index.php?title=Ratio_Decidendi (20 de agosto de 2014).

XIOL, J., 2006: «Notas sobre la jurisprudencia», en V. FERRERES y J. XIOL, El carácter vinculante de la jurisprudencia.

STONE, J., 1959: «The Ratio of a Ratio Decidenci», en Modern Law Review, 22, 6.

TROPER, M., 1996: «La forza dei precedenti e gli effetti perversi del diritto», en Ragion Pratica, 6.

VeluZzI, V., 2011: «Analogia giuridica, common law, precedente giudiziale», en V. VeLuzZI y L. Pelliccioli (eds.), L'analogia nel diritto, Pisa, ETS.

WALDRON, J., 2012: «Stare Decisis and the Rule of Law: a Layered Approach», en Michigan Law Review, 111.

WroblewSKI, J., 2008: «Concepto y función del precedente en sistemas de Statutory Law», en Sentido y hecho en el derecho, México: Fontamara.

ZORZETTO, S., 2010: La norma speciale: una nozione ingannevole, Pisa, ETS. 